\title{
Psychometric Properties of Social Perception of Mathematics: Rasch Model Analysis
}

\author{
Rommel M. A. Al Ali ${ }^{1} \&$ Rami T. Shehab ${ }^{1}$ \\ ${ }^{1}$ King Faisal University, Al-Ahsa, Saudi Arabia \\ Correspondence: Rommel M. A. Al Ali, King Faisal University, Al-Ahsa 31982, Box 1881, Saudi Arabia. \\ E-mail: ralali@kfu.edu.sa
}

Received: May 12, 2020

Accepted: July 9, $2020 \quad$ Online Published: November 28, 2020

doi:10.5539/ies.v13n12p102

URL: https://doi.org/10.5539/ies.v13n12p102

\begin{abstract}
Social perception is an evaluation process, which uses any information available in order to form impressions, understanding, and judgments about others. It is also considered as an essential element of social skills. This study aims to examine the psychometric analysis of students' social perceptions of mathematics using Rasch model analysis. This study uses a quantitative survey approach. The sample comprised 40 first year students at King Faisal University. The Rasch model is used because it is considered an effective tool for assessing constructs' validity and reliability of the instrument. It also generalizes results and inferential studies. The developed questionnaire consists of six dimensions. Every dimension consists of six items. They are verifying the validity based on the Rasch model using item polarity, item fit, and dimensionality. In addition, the reliability was verified using person and item reliability, and item and person separation. The results of the Rasch model analysis show that the items of social perception of mathematics SPoM fit the model appropriately.
\end{abstract}

Keywords: social perception, Rasch model, validity, reliability

\section{Introduction}

Students' perceptions of mathematics play an important role in mathematics education and are closely related to students' learning outcomes. Social perception is concerned with how individuals interpret and respond to their behavior and the conclusions they draw from the actions and results of others (Molden \& Dweck, 2006). Perceptions include a cognitive dimension that relates to a person's knowledge, beliefs and cognitive representations, and the emotional dimension of a person's attitudes, feelings, and emotions about mathematics (Mutodi \& Ngirande, 2014). Difficulty of mathematics related to cognitive components of social perception which are highly varied among students. Anxiety of mathematics are related to emotional component of social perception which are slightly varied among students (Al Ali, 2016).

Social perception is a process of understanding others. It interprets data to understand student behavior accurately. Forming perceptions towards mathematics leads to an effective role in building curricula (Al Ali, 2016). Social perception form the cognitive domain in the learning processes. Emotional variables such as perceptions towards mathematics affect the practice of teaching which helps them understand the strategies for student learning. It also helps individuals to simplify, solve problems and contradictions, and help them to accept situations (Rayyan, 2010). So many researchers and educators believe that the main reasons for the failure of students in mathematics is due to negative perception towards mathematics. Perceptions and beliefs of the students are considered influential factors on the procedures of learning and teaching in mathematics (Philippou \& Christou, 1998).

There are many studies that have focused on students perceptions towards various topics in mathematics as mathematical proof, mathematical problems, symbols, teaching methods, various achievement goals and cooperative learning (Anapa \& Samkar, 2010; Mashooque, 2009; Ozdemir \& Ovez, 2012; Othman, Bahaludin, Tawil, \& Ismail, 2012; Ampadu, 2012). Also there are many studies focusing on the students' perceptions towards teaching and learning mathematics. Kloosterman, Tassell, Ponniah, and Essex (2008) showed that students believe that mathematics is gender impartial, despite females more strongly than males in this belief. Also female in secondary school grasps beliefs in gender impartiality more strongly than female pre-service teachers. Secondary school students point out males and females realize changes in the method both boys and girls performance and are preserved in mathematics classes. Secondary school males those who think that they are good mathematics 
students incline to have more gender-neutral perceptions than those who think they are normal or underneath. There is no like this style seems for secondary school females.

The study by Al Ali, Ghafar, and Mofreh (2016) aimed to recognize students' perceptions towards mathematics, and are there differences in students' perceptions of mathematics according to gender and residence. The findings showed that there were no statistically significant differences according to gender and residence in students' perceptions toward mathematics, but it was positive and high. The study by Kerwani (2012) showed that the students' responses on the scale were positive. Also there were statistically significant differences in the students' perceptions attributed to the university in favor of Alquds Open University. Whereas variables of gender and academic level and cumulative GPA was neutral. Anapa and Samkar (2010) showed most of the students who believe they are successful in mathematics do not trust their ability to proof, this shows that the students memorize the proofs and evidence, The study also revealed that successful students have a negative view of proving, also the students who believe they are successful in mathematics have positive view about proving. The study by Othman et al. (2012) aimed to clarify the students' perception of cooperative learning in the decision of Engineering Mathematics, as well as knowledge of the benefits of cooperative learning on individuals and the group. The result showed that cooperative learning is useful for students and contribute to growth of social skills, also second-year students more maturity and seriousness in making decisions.

The study by Mutodi and Ngirande (2014) examined the impact of student' perceptions on mathematics performance at secondary school. The findings showed that there were statistically significant differences in perceptions and beliefs about mathematics between male and female, and between mature and juvenile. There were strong positive relationships between performance and dimensions of perceptions such as self-confidence and interest in mathematics. Students also view the difficulty of mathematics as an obstacle. The study by Hughes (2009) aimed to finding students' perceptions of teaching styles in mathematics learning environments and their preferred teaching styles. The results showed that, use of assessment strategies with interactive educational strategies to promote student learning is good, also actions of students and teachers in the classroom resulting feedback that is used to make adjustments in the teaching-learning process, finally, comfort, the types of interactive assessment, and education through technology, enhances student learning, and develop teaching-learning process. The study by Schoenfeld (1989) showed that the students' motivation was high, their hardworking, the students treated with respect, they claim that mathematics help them at logical thinking and creative, also claimed that memorization best way to learn mathematics. The study by Eleftherios and Theodosios (2007) showed that students' beliefs and attitudes are independent from their social status, and girls believe more than boys that mathematical understanding is achieved through procedures, also love of mathematics correlate positively with studying mathematics, high performance and mathematical ability, in addition to procedural view and procedural studying of mathematics correlate negatively with performance in mathematics and the ability to understand proofs. The study by Abed and Saeedi (2002) showed that statistically significant differences were found in the mean scores of students beliefs about mathematics and science, there were also statistically significant differences between the means of the students' beliefs about mathematics math and science that can be attributed to the levels of their achievement.

According to the National Center for Assessment in Higher Education, there is a significant weakness in the basic mathematical principles of most students in universities (Al Ali, 2016). Many students are afraid and worried about mathematics, and consider it difficult, abstract and uncreative (Mutodi \& Ngirande, 2014). This due to the negative perception towards mathematics, so many researchers and educators believe that the main reasons for the failure of students in mathematics due to negative perception towards it. Also accompanies these perceptions from different educational aspects such as hate for mathematics and low achievement and poor attention. The study of perception towards mathematics guide the behavior of the learner about precision and organization, confidence and self-reliance in solving problems, and objectivity in judging the attitudes and things, and the formation of motivation and desire to continue to study and learn (Abdul Hamid, 2012). The impact of social perceptions on individuals plays an important role in their lives. It directs the behavior to descript phenomenon through social, psychological and biological framework, so that individuals remain connected to the community. This study aimed to use the Rasch Model analysis because it is considered an effective tool for assessing constructs validity and reliability of the instrument in order to use it for develop scale about social perception of mathematics. This study aimed to verify the validity and reliability of instrument in order to measure the students' social perception towards mathematics.

\section{Rasch Model}

Rasch developed a special model, to estimate the abilities of individuals through their responses on the test items (McCamey, 2014). Rasch model helps to predict probability of the correct answer on a test based on an estimate 
items two variables which are difficulty of item and ability of the individual through joint continuity between them (De Battisti, Salini, \& Crescentini, 2004). Rasch model analysis improves the accuracy and quality of tests and surveys, as it also allows the creation of multiple forms of measuring instruments. When using survey data, it makes important corrections and clarifies meaning of student and group metrics using survey items (Boone, 2016).The construction of any achievement test according to Rash model provides the advantages of accuracy, objectivity and independence in the measurement. Rasch model is taken as a criterion for the structure of the responses, rather than a mere statistical description of the responses. Rasch model is used in order to reach the highest level of accuracy and objectivity in the measurement in order to achieve more accurate relationship between measuring tool and underlying attribute of the individual (Nunnally, 1994). Rasch Model analysis is a powerful tool for evaluating constructs validity and reliability of the instrument (Mofreh, Ghafar, Omar, Mosaku, \& Ma'ruf, 2014).

The Rasch model is a probabilistic unidimensional model which confirms that, the easier the question the more likely the student will respond correctly to it, and also, the more able the student, the more likely he/she will pass the question compared to a less able student. In constructing tests using this model frequently discard those items that do not meet these assumptions (Wright \& Stone, 1979). Rasch analysis gives the reliability coefficient for each person and item (El-Korashy, 1995). The simplest models provide parameter invariance. Include minimal number of parameters. Parameters have simple interpretation, can be easily estimated and be applied to all item types which use in educational and psychological tests. All specific testing problems can be easily solved.

In Rasch the model is superior. Data which does not fit the model is discarded. Rasch does not permit abilities to be estimated for extreme items and persons and other differences. The model assumes that the probability that a student will correctly answer a question is a logistic function of the difference between the student's ability and the difficulty of the question. The Rasch model offers a unified framework under which all of the assumptions can be tested together. It gives us a lot of information about individual items which can be utilized to ensure that item and test construction is of a high quality. It provides a rigorous mathematical basis for test equating.

\section{Methodology}

This study is a pilot study aims to verify the validity and reliability of instrument in order to measure the students' social perception towards mathematics. It used a quantitative descriptive survey approach, .because the findings are logical and can be generalized.

\subsection{Population and Sample}

The population of this study consisted of all first-year students for undergraduate at King Faisal University. The sample of the pilot study has been randomly selected of all colleges at King Faisal University which consisted of (40) students.

\subsection{Instrument}

A questionnaire was developed after reviewing the previous studies based on the standards criteria of Rasch model analysis. The questionnaire includes 36 items divided into six dimensions of data collection which are difficulty of mathematics includes 6 items (B1, B7, B13, B19, B25 \& B3), usefulness of mathematics includes 6 items (B3, B9, B15, B21, B27 \& B33), enjoyment of mathematics includes 6 items (B5, B11, B17, B23, B29 \& B35), anxiety of mathematics includes 6 items (B4,B10, B16, B22, B28 \& B34), the nature of mathematics includes 6 items (B2, B8, B14, B20, B26 \& B32) and teacher role includes 6 items (B6, B12, B18, B24, B30 \& $\mathrm{B} 36(\mathrm{Al} \mathrm{ALi}, 2016)$. Progressive scale of five categories was used for this questionnaire that consist of $1=$ strongly disagree, 2 = disagree, $3=$ uncertain, $4=$ agree, and $5=$ strongly agree. After that, the questionnaire was applied to the study sample in order to achieve the objective of the study. Verifying the validity and reliability of the questionnaire based on Rasch model.

\section{Results}

Quantitative data of developed social perception of mathematics questionnaire was analyzed by using Winsteps version 3.68.2 in order to verify the questionnaire items validity and reliability. To ensure the validity according to Rasch model, it should be achieved from the following standards criteria:

1) Item-fit Statistics. It divided into two kinds, which are; outfit statistics and infit statistics. If the value of mean square (MNSQ) for infit lies between 0.4 and 1.5 then the values are appropriate.

2) Item polarity analysis (point measure correlation PTMEA) is necessary to find construct validity. If the value of PTMEA lies between 0.2 and 1 then the values are appropriate and acceptable based on Rasch model (Strong, Breen, Lesieur, \& Lejuez, 2005; Pesudovs, Garamendi, Keeves, \& Elliott, 2003; Bond \& Fox, 2007; 
Linacre, 2006).

3) Calibration Scaling Analysis also used to determine the validity.

Reliability in Rasch measurement refers to the degree to which measurement error is not present in the model (Smith, 2004). Reliability is measured in terms of both person and item reliability. To ensure the reliability according to Rasch model, it should be achieved from the following standards criteria:

1) Person and Item Reliability, in Rasch model the value of reliability should be more than 0.50 (Bond \& Fox, 2007; Linacre, 2007).

2) Item separation indicated to all respondents was able to response all the items. The appropriate value for separation should be more than 2 (Wright \& Masters, 1982; Fisher, 2007).

Summary of RM analysis results of the developed SPMQ as followed.

\subsection{Item Polarity and Item Fit Analysis}

Item polarity analysis (The point-measure correlations PTMEA Corr) is necessary to find construct validity (Bond \& Fox, 2007). The OUTFIT mean-square statistic is the average of the squared standardized-residual for the responses by a person, or on an item. The INFIT mean-square is the information-weighted average of the squared residuals. Table 1 below shows that the value of PTMEA and MNSQ.

Table 1. Item fit analysis for social perception of mathematics

\begin{tabular}{|c|c|c|c|c|c|c|c|c|c|c|c|c|c|}
\hline \multirow{2}{*}{$\begin{array}{l}\text { Entry } \\
\text { No } \\
28\end{array}$} & \multirow{2}{*}{ 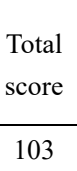 } & \multirow{2}{*}{$\begin{array}{c}\text { Count } \\
40\end{array}$} & \multirow{2}{*}{$\begin{array}{c}\text { Measure } \\
.51\end{array}$} & \multirow{2}{*}{$\begin{array}{c}\text { Model } \\
\text { S.E } \\
.16\end{array}$} & \multicolumn{2}{|c|}{$\begin{array}{c}\text { Infit } \\
\text { MNSQ } \\
\text { ZSTD }\end{array}$} & \multicolumn{2}{|c|}{$\begin{array}{c}\text { outfit } \\
\text { MNSQ } \\
\text { ZSTD }\end{array}$} & \multicolumn{2}{|c|}{$\begin{array}{c}\text { Pt-measure } \\
\text { CORR } \\
\text { EXP }\end{array}$} & \multirow{2}{*}{$\begin{array}{c}\text { Exact } \\
\text { OBS\% }\end{array}$} & \multirow{2}{*}{$\begin{array}{c}\text { Match } \\
\text { EXP\% }\end{array}$} & \multirow{2}{*}{$\begin{array}{l}\text { items } \\
\text { B28 }\end{array}$} \\
\hline & & & & & 1.08 & .4 & 1.46 & 1.8 & .43 & .56 & & & \\
\hline 27 & 133 & 40 & .01 & .15 & 1.38 & 1.7 & 1.45 & 1.7 & .49 & .64 & 30.0 & 37.2 & B27 \\
\hline 4 & 89 & 40 & 1.05 & .16 & 1.32 & 1.5 & 1.41 & 1.3 & .41 & .54 & 32.5 & 36.6 & B4 \\
\hline 32 & 121 & 40 & .17 & .16 & 1.31 & 1.5 & 1.37 & 1.6 & .42 & .60 & 32.5 & 40.8 & B32 \\
\hline 21 & 124 & 40 & .23 & .15 & 1.17 & .9 & 1.37 & 1.5 & .54 & .62 & 32.5 & 37.6 & B21 \\
\hline 12 & 157 & 40 & -.18 & .18 & 1.24 & 1.1 & 1.28 & 1.0 & .51 & .60 & 47.5 & 43.4 & B12 \\
\hline 20 & 149 & 40 & -.48 & .17 & 1.17 & .8 & 1.28 & 1.1 & .57 & .65 & 27.5 & 37.0 & B20 \\
\hline 34 & 134 & 40 & .04 & .15 & 1.20 & 1.0 & 1.27 & 1.0 & .50 & .64 & 25.0 & 37.8 & B34 \\
\hline 2 & 147 & 40 & -.27 & .15 & 1.03 & .2 & 1.26 & .9 & .58 & .66 & 30.0 & 39.3 & B2 \\
\hline 6 & 169 & 40 & -.71 & .20 & .92 & -.1 & 1.20 & .6 & .74 & .70 & 70.0 & 61.2 & B6 \\
\hline 24 & 136 & 40 & -.21 & .17 & 1.17 & .9 & 1.11 & .6 & .54 & .62 & 30.0 & 39.0 & B24 \\
\hline 23 & 164 & 40 & -.63 & .19 & 1.17 & .6 & 1.16 & .5 & .64 & .70 & 50.0 & 53.6 & B23 \\
\hline 10 & 119 & 40 & .29 & .17 & 1.10 & .5 & 1.13 & .7 & .53 & .60 & 35.0 & 40.7 & B910 \\
\hline 11 & 148 & 40 & -.73 & .18 & 1.10 & .5 & .94 & -.2 & .60 & .62 & 50.0 & 46.2 & B11 \\
\hline 26 & 144 & 40 & -.09 & .16 & 1.01 & .1 & 1.08 & .3 & .65 & .67 & 37.5 & 39.9 & B26 \\
\hline 14 & 149 & 40 & -.37 & .81 & 1.06 & .3 & 1.01 & .1 & .65 & .67 & 47.5 & 45.1 & B14 \\
\hline 15 & 136 & 40 & -.09 & .15 & 1.00 & .1 & 1.01 & .1 & .65 & .64 & 37.5 & 35.3 & B15 \\
\hline 18 & 170 & 40 & -.89 & .21 & .96 & .0 & 1.00 & .1 & .70 & .70 & 62.5 & 59.3 & B18 \\
\hline 36 & 144 & 40 & -.29 & .18 & .99 & .0 & 1.00 & .1 & .61 & .65 & 35.0 & 49.4 & B36 \\
\hline 33 & 137 & 40 & -.14 & .16 & 1.00 & .1 & .98 & .0 & .61 & .63 & 37.5 & 39.2 & B33 \\
\hline 9 & 120 & 40 & .28 & .17 & .98 & .0 & .97 & -.1 & .63 & .60 & 35.0 & 40.5 & B9 \\
\hline 29 & 144 & 40 & -.26 & .17 & .96 & -.1 & .97 & .0 & .67 & .65 & 40.0 & 42.1 & B29 \\
\hline 5 & 149 & 40 & -.34 & .16 & .91 & -.3 & .91 & -.2 & .71 & .66 & 42.5 & 43.2 & B5 \\
\hline 31 & 93 & 40 & .80 & .15 & .87 & -.5 & .91 & -.2 & .59 & .54 & 45.0 & 38.6 & B31 \\
\hline 30 & 134 & 40 & .06 & .15 & .90 & -.4 & .85 & -.5 & .67 & .64 & 30.0 & 36.7 & B30 \\
\hline 8 & 167 & 40 & -.90 & .23 & .78 & -.5 & .90 & -.2 & .72 & .70 & 52.5 & 57.4 & B8 \\
\hline 1 & 86 & 40 & .93 & .16 & .84 & -.6 & .71 & -1.0 & .59 & .52 & 45.0 & 42.2 & $\mathrm{~B} 1$ \\
\hline 19 & 117 & 40 & .20 & .16 & .83 & -.8 & .78 & -1.0 & .69 & .59 & 47.5 & 41.4 & B19 \\
\hline 35 & 115 & 40 & .44 & .15 & .78 & -1.1 & .74 & -1.0 & .68 & .60 & 42.5 & 35.3 & B35 \\
\hline 13 & 110 & 40 & .45 & .16 & .76 & -1.2 & .70 & -1.4 & .70 & .59 & 55.0 & 39.8 & B13 \\
\hline 25 & 86 & 40 & 1.08 & .16 & .76 & -1.2 & .64 & -1.3 & .64 & .53 & 42.5 & 38.9 & B25 \\
\hline 3 & 150 & 40 & -.34 & .18 & .75 & -.9 & .71 & -1.0 & .75 & .67 & 47.5 & 47.6 & B3 \\
\hline 17 & 124 & 40 & .21 & .14 & .73 & -1.5 & .69 & -1.3 & .73 & .62 & 40.0 & 34.6 & B17 \\
\hline
\end{tabular}




\begin{tabular}{ccccccccccccccccccc}
\hline 16 & 122 & 40 & .28 & .15 & .69 & -1.7 & .66 & -1.6 & .74 & .61 & 45.0 & 38.5 & B16 \\
7 & 145 & 40 & -.10 & .14 & .68 & -1.4 & .57 & -1.2 & .75 & .66 & 40.0 & 39.0 & B 7 \\
22 & 132 & 40 & -.01 & .15 & .59 & -2.3 & .62 & -1.8 & .77 & .62 & 42.5 & \\
\hline
\end{tabular}

Table 1 shows that the value of PTMEA is ranging from 0.41 to 0.77 . Also shows all correlation measures positive and well improved. Therefore, the values are appropriate and acceptable for construct validity according to Rasch model. Furthermore, Table 1.1 shows that the value of MNSQ for infit lies between 0.59 and 1.38 . These values are appropriate and acceptable for construct validity according to Rasch model. The results for category fit shows that item mean squared INFIT is 0.97 and the item mean squared OUTFIT is ranging from 1.02 to 1.20 . This shows that all categories functioning well, there are two response scales in our study, scale 1 represents agreement and scale 0 represents disagreement. For the category measure, the measurement functioning as expected.

\subsection{Calibration Scaling Analysis}

To find the validity of the instrument according to Rasch model is to make zero calibration and subsequent grading instrument (Mofreh et al., 2014). Table 2 below shows the calibration scaling analysis of SPoM.

Table 2. Calibration scaling analysis of social perception of mathematics SPoM questionnaire

\begin{tabular}{|c|c|c|c|c|c|c|c|c|c|}
\hline $\begin{array}{c}\text { Category } \\
\text { Label }\end{array}$ & Score & $\begin{array}{c}\text { Observed } \\
\text { Count } \%\end{array}$ & $\begin{array}{l}\text { Observed } \\
\text { Average }\end{array}$ & $\begin{array}{l}\text { Sample } \\
\text { Expect }\end{array}$ & $\begin{array}{c}\text { Infit } \\
\text { MNSQ }\end{array}$ & $\begin{array}{c}\text { Outfit } \\
\text { MNSQ }\end{array}$ & $\begin{array}{c}\text { Structure } \\
\text { Calibration }\end{array}$ & $\begin{array}{l}\text { Category } \\
\text { Measure }\end{array}$ & \\
\hline 1 & 1 & $\begin{array}{l}14 \\
35\end{array}$ & -.42 & -.33 & .91 & .94 & None & $(-1.30)$ & 1 \\
\hline 2 & 2 & $\begin{array}{l}16 \\
40\end{array}$ & .33 & .29 & .89 & .55 & -1.03 & .32 & 2 \\
\hline 3 & 3 & $\begin{array}{l}3 \\
8\end{array}$ & .52 & .57 & .94 & .65 & 1.19 & 1.04 & 3 \\
\hline 4 & 4 & $\begin{array}{c}4 \\
10\end{array}$ & .84 & .82 & .83 & .60 & -.53 & 1.65 & 4 \\
\hline 5 & 5 & $\begin{array}{l}3 \\
8\end{array}$ & 1.47 & 1.23 & .75 & .66 & .37 & $(2.74)$ & 5 \\
\hline
\end{tabular}

Table 2 shows that the most frequent answer is the scale of participants ranking 2 which $16(40 \%)$. The second grading scale was scale 1 of $14(35 \%)$. Then the third grading scale was scale 4 of $4(10 \%)$. Finally, the lower grading scale was scales 3 and 5 with $3(8 \%)$. The column 4 which is observed averages show the pattern of participants move from negative to positive (-.42 to 1.47). Based on Rasch model this indicates to normal pattern.

\subsection{Dimensionality Analysis}

Dimensionality is essential to ensure content validity and construct validity of the instrument. It also used for determining the instrument in one direction and one dimension. The standards for dimensionality are more than of 40\% (Linacre, 2003; Bond \& Fox, 2007; Wu \& Adams, 2007). If the raw variance explained by measures was more than $40 \%$ and explained variance in 1 st contrast was less than 15 then the dimensionality is appropriate or acceptable according to Rasch model. Table 3 below shows item dimensionality of SPoM. 
Table 3. Item dimensionality of SPoM questionnaire

\begin{tabular}{|c|c|c|c|c|c|c|}
\hline & \multicolumn{4}{|c|}{ Empirical } & & \multirow{2}{*}{$\begin{array}{c}\text { Modeled } \\
100 \%\end{array}$} \\
\hline Total raw variance in observations & & 76.6 & & $100 \%$ & & \\
\hline Raw variance explained by measures & & 40.6 & & $53.0 \%$ & & $48.8 \%$ \\
\hline Raw variance explained by persons & & 17.4 & & $22.7 \%$ & & $20.9 \%$ \\
\hline Raw Variance explained by items & & 23.2 & & $30.3 \%$ & & $27.9 \%$ \\
\hline Raw unexplained variance (total) & 36. & & $47.0 \%$ & & $100 \%$ & $51.2 \%$ \\
\hline Unexplained variance in 1 st contrast & 4 & & $5.7 \%$ & & $12.0 \%$ & \\
\hline Unexplained variance in 2 nd contrast & 3.3 & & $4.3 \%$ & & $9.1 \%$ & \\
\hline Unexplained variance in $3 \mathrm{rd}$ contrast & 3.1 & & $4.0 \%$ & & $8.5 \%$ & \\
\hline Unexplained variance in 4 th contrast & 2.7 & & $3.5 \%$ & & $7.4 \%$ & \\
\hline Unexplained variance in 5 th contrast & 2.2 & & $2.9 \%$ & & $6.2 \%$ & \\
\hline
\end{tabular}

Table 3 shows that the raw variance explained by measures was $53.0 \%$, and explained variance in 1 st contrast was $5.7 \%$. Therefore, dimensionality data results are appropriate to Rasch model. Tables 4 and 5 below show that the Item and Person separation and reliability and Item and Person separation for SPoM questionnaire.

Table 4. Person separation and reliability for SPoM questionnaire

\begin{tabular}{cccccccccc}
\hline & \multirow{2}{*}{ Score } & \multirow{2}{*}{ Count } & \multirow{2}{*}{ Measure } & \multirow{2}{*}{ Error } & \multicolumn{3}{c}{ Infit } & \multicolumn{2}{c}{ Outfit } \\
\cline { 6 - 9 } & & & & & IMSQ & ZSTD & IMSQ & ZSTD \\
\hline Mean & 35.2 & 24.0 & -.63 & .23 & 1.03 & -.1 & 1.04 & .0 \\
S.D & 252.6 & .0 & .44 & .01 & .20 & 3.2 & .30 & 3.2 \\
Real rmse & .05 & & & & & & & \\
Adj. sd & .43 & & & & & & & \\
Separation & 9.46 & & & & & & & \\
Person reliability & .89 & & & & & & & \\
\hline
\end{tabular}

Table 5. Item separation and reliability for SPoM questionnaire

\begin{tabular}{cccccccccc}
\hline & \multirow{2}{*}{ Score } & \multirow{2}{*}{ Count } & \multirow{2}{*}{ Measure } & \multirow{2}{*}{ Error } & \multicolumn{3}{c}{ Infit } & \multicolumn{2}{c}{ Outfit } \\
\cline { 5 - 9 } & & & & & IMSQ & ZSTD & IMSQ & ZSTD \\
\hline Mean & 729.5 & 500.0 & .00 & .05 & 1.01 & .0 & 1.04 & .4 \\
S.D & 18.4 & .0 & .76 & .10 & .41 & 1.5 & .46 & 1.3 \\
Real rmse & .25 & & & & & & & \\
Adj. sd & .72 & & & & & & & \\
Separation & 2.85 & & & & & & & \\
Item reliability & .99 & & & & & & & \\
\hline
\end{tabular}

Table 4 shows that the person reliability was .89 and the person separation was 9.46 . Table 5 shows that the items reliability was .99 and the person separation was 2.85 . Both person and item reliability was greater than 0.5 . Based on Rasch model these reliability values indicate that the test has a good degree of reliability.

\subsection{Reliability Analysis}

Reliability in Rasch measurement refers to the degree to which measurement error is not present in the model (Smith, 2004). Reliability is measured in terms of both person and item reliability. To ensure the reliability according to Rasch model, it should be achieved from the following; Person and Item Reliability, person and Item separation. 
Table 6. Person separation and reliability

\begin{tabular}{cccccccccc}
\hline & \multirow{2}{*}{ Total Score } & \multirow{2}{*}{ Count } & \multirow{2}{*}{ Measure } & \multirow{2}{*}{ Model Error } & \multicolumn{3}{c}{ Infit } & \multicolumn{2}{c}{ Outfit } \\
\cline { 6 - 9 } & & & & & & IMSQ & ZSTD & IMSQ & ZSTD \\
\hline Mean & 119.2 & 36.0 & .22 & .18 & .96 & -.3 & 1.00 & -.1 \\
S.D & 29.0 & .0 & .90 & .05 & .42 & 1.8 & .48 & 1.7 \\
Max. & 172.0 & 36.0 & 2.46 & .35 & 2.05 & 3.9 & 2.40 & 4.3 \\
Min. & 46.0 & 36.0 & -2.17 & .15 & .39 & -3.4 & .39 & -3.2 \\
Real rmse & .20 & & & & & & & \\
Adj. sd & .88 & & & & & & & & \\
Separation & 4.35 & & & & & & & & \\
Person reliability & .95 & & & & & & & &
\end{tabular}

Table 7. Item separation and reliability

\begin{tabular}{cccccccccc}
\hline & \multirow{2}{*}{ Total Score } & \multirow{2}{*}{ Count } & \multirow{2}{*}{ Measure } & \multirow{2}{*}{ Model Error } & \multicolumn{2}{c}{ Infit } & \multicolumn{3}{c}{ Outfit } \\
\cline { 6 - 9 } & & & & & & & \\
& & & & & & & \\
MSQ & ZSTD & IMSQ & ZSTD \\
\hline S.D & 22.4 & 40.0 & .00 & .17 & .98 & -.1 & 1.00 & .0 \\
Max. & 170.0 & 40.0 & 1.08 & .23 & 1.38 & 1.7 & 1.46 & 1.8 \\
Min. & 86.0 & 40.0 & -.90 & .14 & .59 & -2.3 & .57 & -1.8 \\
Real rmse & .17 & & & & & & & \\
Adj. sd & .46 & & & & & & & & \\
Separation & 2.69 & & & & & & & & \\
Item reliability & .89 & & & & & & & & \\
\hline
\end{tabular}

Table 6 shows the person reliability for construct. Reliability for a person is estimating consistency of an individual ranking on the logit scale if the sample answers different set of item to measure the same construct (Wright \& Master in Bond \& Fox, 2001). Person reliability was very high with .95 , and the person separation was 4.35 . So this value is appropriate based on Rasch model. Table 7 shows the item reliability. The reliability of the item is the estimation of the consistency of the item placement on the logit scale if the item is answered by a group of different sample which possess the same ability (Bond \& Fox, 2001). Item reliability was high with .89, and the item separation was 2.69. So this value is appropriate based on Rasch model. Therefore, the reliability of person and item reliability for SPoM questionnaire is acceptable based on Rasch model.

\section{Conclusion}

This study uses Rasch model analysis to assess the usefulness of several items used in students' social perception of mathematics in order to modify some teaching practices such as teaching methods and strategies, assessment and evaluation tools, and the educational environment to suit students 'interest and reach to a positive perception towards mathematics. This paper aimed to use the Rasch Model analysis because it is considered an effective tool for assessing constructs validity and reliability of the instrument in order to use it to develop scale for social perception of mathematics SPoM. The study answered that the items of students' social perception of mathematics questionnaire contain adequate and sufficient fit statistics. It also according to our results in the study, after evaluating SPoM defined items; item reliability, item separation, dimensionality, and evaluation of Rasch model fit, it is found that all items are suitable for the measurement of SPoM construct based on the Rasch analysis measurement and with good psychometric properties.

\section{Recommendations}

1) The study recommends the adoption of the instrument of social perception of mathematics from educators and interested in the educational process, in order to know students' perceptions towards mathematics, to promote and encourage the positive perceptions, and to modify negative perceptions towards mathematics.

2) Conducting further studies by addressing new dimensions.

\section{References}

Abdul Hamid, A. (2012). The importance of studying students' perceptions towards mathematics. Resalat aljamea, No. 1166.

Abed, A., \& Saeedi, A. (2002). High school students' beliefs about math and science, and some related variables. 
Journal of Educational and Psychological Sciences, 3(14), 125-150. https://doi.org/10.12785/JEPS/030305

$\mathrm{Al}$ Ali, R. M. (2016). Assessment of social perceptions and mathematical thinking amongst Jordanian students in higher education (Unpublished doctoral dissertation). University Technology Malaysia, Malaysia.

Al Ali, R. M., Ghafar, M. N., \& Mofreh, S. A. (2016). Social perceptions of mathematics among Jordanian higher education students. Journal of Institutional Research South East Asia, 14(1), 112-126.

Ampadu, E. (2012). Students' Perceptions of their Teachers' Teaching of Mathematics: The Case of Ghana. International Online Journal of Educational Sciences, 4(2), 351-358.

Anapa, P., \& Şamkar, H. (2010). Investigation of undergraduate students' perceptions of mathematical proof. Procedia-Social and Behavioral Sciences, 2(2), 2700-2706. https://doi.org/10.1016/j.sbspro.2010.03.399

Bond, T. G., \& Fox, C. M. (2007). Applying the RM: Fundamental Measurement in the Human Sciences. Published by Lawrence Erilbaum Associations, Publishers, Marthwah, New Jersey, and London.

Boone, W. J. (2016). Rasch analysis for instrument development: why, when, and how? CBE-Life Sciences Education, 15(4). https://doi.org/10.1187/cbe.16-04-0148

De Batisti, F.; Salini, S., \& Crescentini, A. (2004). Statistical calibration of psychometric tests. Dipartimento Di Economia Politica e Aziendal. University Degli Studidi Milan.

Dunning, D. (2001). What Is the Word on Self-Motives and Social Perception: Introduction to the Special Issue. Motivation and Emotion, 25(1), 1-6. https://doi.org/10.1023/A:1010627820999

Eleftherios, K., \& Theodosios, Z. (2007). Students' beliefs and attitudes about studying and learning mathematics. In Proceedings of the 31st Conference of the International Group for the Psychology of Mathematics Education, 3, 97-104.

El-Korashy, A. (1995). Applying the Rasch Model to the Selection of Items for a Mental Ability Test. $\begin{array}{llll}\text { Educational and } & \text { 753-763. }\end{array}$ https://doi.org/10.1177/0013164495055005006

Fisher, A. G., \& Fischl, C. (2007). Development and Rasch analysis of the Assessment of Computer-Related Skills. Scandinavian Journal of Occupational Therapy, 14(2), 126-135. https://doi.org/10.1080/11038120600840192

Hughes, G. B. (2009). Students' Perceptions of Teaching Styles in Mathematics Learning Environments. Mathematics Teaching-Research Journal Online, 3(2), 1-12.

Jussim, L. (2012). Social perception and social reality. New York. Oxford university press, Inc. https://doi.org/10.1093/acprof:oso/9780195366600.001.0001

Kerawani, M. (2012). Attitudes of mathematics and computer students at Al-Quds Open University in Salfeet educational region towards e-learning application in mathematics. Palestinian Journal of Open Education, $3(6)$.

Kloosterman, P., Tassell, J. H., Ponniah, A. G., \& Essex, N. K. (2008). Perceptions of mathematics and gender. School Science and Mathematics, 108(4), 149-162. https://doi.org/10.1111/j.1949-8594.2008.tb17821.x

Linacre, J. M. (2006). Data variance explained by Rasch measures. Rasch Measurement Transactions, 20(1), 1045.

Mashooque A. S. (2009). Students' perceptions about the symbols, letters and signs in algebra and how do these affect their learning of algebra: A case study in a government girls secondary school Karachi. International Journal for Mathematics Teaching and Learning.

McCamey, R. (2014). A primer on the one-parameter Rasch model. American Journal of Economics and Business Administration, 6(4), 159. https://doi.org/10.3844/ajebasp.2014.159.163

Mofreh, S. A. M., Ghafar, M. N., Omar, A. H. H., Mosaku, M., \& Ma'ruf, A. (2014). Psychometric Properties on Lecturers' Beliefs on Teaching Function: Rasch Model Analysis. International Education Studies, 7(11), 47. https://doi.org/10.5539/ies.v7n11p47

Molden, D. C., \& Dweck, C. S. (2006). Finding "meaning" in psychology: a lay theories approach to self-regulation, social perception, and social development. American Psychologist, 61(3), 192. https://doi.org/10.1037/0003-066X.61.3.192

Mutodi, P., \& Ngirande, H. (2014). The Influence of StudentsPerceptions on Mathematics Performance. A Case 
of a Selected High School in South Africa. Mediterranean Journal of Social Sciences, 5(3), 431. http://doi.org/10.5901/mjss.2014.v5n3p431

Nunnally, J. C. (1994). Psychometric Theory 3E. Tata McGraw-Hill Education. New York.

Othman, H., Asshaari, I., Bahaludin, H., Tawil, N. M., \& Ismail, N. A. (2012). Students' Perceptions on Benefits Gained from Cooperative Learning Experiences in Engineering Mathematics Courses. Procedia-Social and Behavioral Sciences, 60, 500-506. https://doi.org/10.1016/j.sbspro.2012.09.414

Ozdemir, E., \& Ovez, F. T. D. (2012). A Research on Proof Perceptions and Attitudes Towards Proof and Proving: Some Implications for Elementary Mathematics Prospective Teachers. Procedia-Social and Behavioral Sciences, 46, 2121-2125. https://doi.org/10.1016/j.sbspro.2012.05.439

Pehkonen, E. (1999). Conceptions and images of mathematics professors on teaching mathematics in school. International Journal of Mathematics Education in Science and Technology, 30(3), 389-397. https://doi.org/10.1080/002073999287905

Pesudovs, K., Garamendi, E., Keeves, J. P., \& Elliott, D. B. (2003). The Activities of Daily Vision Scale for cataract surgery outcomes: re-evaluating validity with Rasch analysis. Investigative ophthalmology \& visual science, 44(7), 2892-2899. https://doi.org/10.1167/iovs.02-1075

Philippou, H., \& Christou, C. (1998). The Effects of a Preparatory Mathematics Program in Changing Prospective Teachers' Attitudes towards Mathematics. Educational Studies in Mathematics, 35(2), 189-206. https://doi.org/10.1023/A:1003030211453

Schoenfeld, A. H. (1989). Explorations of students' mathematical beliefs and behavior. Journal for research in mathematics education, 338-355. https://doi.org/10.2307/749440

Schoenfeld, A. H. (2016). Learning to think mathematically: Problem solving, metacognition, and sense making in mathematics (Reprint). Journal of Education, 196(2), 1-38. https://doi.org/10.1177/002205741619600202

Smith, E. V. (2004). Evidence for the Reliability of Measures and Validity of Measure Interpretation: A Rasch Measurement Perspective. Journal of applied measurement, 2(3), 281.

Strong, D. R., Breen, R. B., Lesieur, H. R., \& Lejuez, C. W. (2005). Using the Rasch model to evaluate the South Oaks Gambling Screen for use with nonpathological gamblers. Addictive Behaviors, 28(8), 1465-1472. https://doi.org/10.1016/S0306-4603(02)00262-9

Wright, B. D., \& Stone, M. H. (1979). Best test design: Rasch measurement. Chicago: MESA Press.

Wright, B., \& Master, G. (1982). Rating Scale Analysis. Rasch Measurement (1st ed.). MESA Press, Chicago.

Wu, M., \& Adams, R. (2007). Applying the Rasch model to psycho-social measurement: A practical approach. Educational Measurement Solutions, Melbourne.

Zebrowski, J. A. (2007). New research on social perception. Nova science publishers. Inc. New York.

\section{Copyrights}

Copyright for this article is retained by the author(s), with first publication rights granted to the journal.

This is an open-access article distributed under the terms and conditions of the Creative Commons Attribution license (http://creativecommons.org/licenses/by/4.0/). 